\title{
Innovation in the Concepts of Intercultural Communication and Resistance to Changes in Responsible Organisations
}

Manu Broccard ${ }^{1 *}$, Alain Pillet ${ }^{1}$ and Jérôme Baratelli ${ }^{2}$

${ }^{1}$ Institute of Tourism, HES-SO Valais, $\mathrm{CH}$-3960 Sierre, Switzerland

${ }^{2}$ Dean of Faculty, Geneva School of Art and Design, 1201 Geneva, Switzerland

\begin{abstract}
The original objective of this project was to reinvent a way of communicating destinations to specific targets. However, resistance to change by politicians and tourists oriented the research challenge towards organizational and human approaches. The question of levers and resistance to change became central, the hypothesis being that the development of an organizational innovation makes the communication strategies of destinations more effective within Swiss tourism companies.

We assessed that the differences in the perception of promotional messages were confronted with a rich and nevertheless self-centered iconographic positioning: Switzerland seen by its own citizens. The scientific objectives of this project attempt to demonstrate that a type of organization managing a co-creation process with all stakeholders can enhance a new communication paradigm by significantly reducing resistances to change within Swiss touristic organizations.
\end{abstract}

Keywords: Governance; Communication; Interculturality organisational innovation; Swissness; Resistance to change

\section{Introduction}

\section{Genesis}

Globalization has opened new markets to the most important Swiss destinations. They are now looking for customers in markets as diverse as China, the Middle East, Brazil and Australia. These changes imply a questioning of how to communicate on the part of the destinations. Targeted marketing for local markets will not work with different culture receptors. These can lead to lasting misunderstandings due to a very different approach to travel and a wide variety of expectations about the destination and its services.

One of the main characteristics of communication is to adapt to its target (receiver), this is all the more so as in the intercultural context. Messages prepared with a European or North American vision and sensitivity will have little impact on an Asian or African target. According to Mkono, companies or destinations that will become aware of these differences and will tailor their messages will have a certain competitive advantage. "A 'one size fits all' approach is outdated in today's globalized world of business" [1].

In addition, recent developments in marketing demonstrate that the barrier between companies (issuers) and customers (receivers) is becoming increasingly permeable [2]. The concept of customer's commitment in communication adds up to the many other opportunities available to the client to influence the development of the company. This tends to prove all the interest a message sender can find in co-creating it with his target in order to ensure a successful communication.

In the tourism sector, the evolution of overnight stays in Switzerland clearly demonstrates the advent of new, culturally distant markets [3]. The Chinese market, for example, grew by $521 \%$ between 2000 and 2013 to set up at 994546 overnight stays, representing 5\% of the total [3]. In comparison, the Gulf States market (GCC) grew by an annual average increase of $19.8 \%$ between 2005 and 2013. It now represents $3.2 \%$ of all markets. This forces destinations to rethink their communication and adapt new techniques that can guarantee their competitive advantage.

Opening a door to a new era in destination marketing at the global level is a challenge as traditional models have reached their limits. The economic challenge is to open up new market shares while providing coherent communication for message recipients, i.e. new clients of a culture distant from our own.

This "strategic" objective, based on the notion of innovation, does not take into account the human impact of the tensions from the point of view of the collaboration generated by the confrontations between representations and ideas. This tension reveals that few managers are truly aware of the strategic management of change and that company executives are content to manage change from a strictly operational point of view, obscuring a strategic and cognitive logic which is necessary for the successful conduct of change [4].

An innovative organization requires a managerial transformation that relies on both emotional and intellectual skills. "En tant qu'élément du contexte, d'un contexte intangible, les représentations structurent les comportements des acteurs mais elles sont également révélatrices des structurations de l'organisation sur les acteurs. Sans croire à une causalité linéaire entre représentation et action, nous soutenons l'idée qu'il existe une relation forte entre ces deux pôles et que l'analyse des représentations est un élément essentiel, bien que peu développé dans la littérature sur le changement, dans la compréhension du processus et des difficultés de gestion du changement organisationnel" [5].

*Corresponding author: Manu Broccard, Institute of Tourism, HES-SO Valais CH-3960 Sierre, Switzerland, Tel: +41 2760690 68; E-mail: manu.broccard@hevs.ch

Received October 03, 2017; Accepted October 19, 2017; Published October 26, 2017

Citation: Broccard M, Pillet A, Baratelli J (2017) Innovation in the Concepts of Intercultural Communication and Resistance to Changes in Responsible Organisations. J Tourism Hospit 6: 314. doi: 10.4172/2167-0269.1000314

Copyright: (c) 2017 Broccard M, et al. This is an open-access article distributed under the terms of the Creative Commons Attribution License, which permits unrestricted use, distribution, and reproduction in any medium, provided the original author and source are credited. 


\section{Concepts and Methodology}

\section{State of the art from a marketing perspective}

Marketers and other commercial message providers have a responsibility to define the image they give of themselves and their companies (positioning) through their speech. This refers to their credibility and the confidence they should rise among their targets (receivers). As stated by Barthes, this communication is linked to three key elements: the issuer, which must have an ethic to be credible; the message, which must include good arguments; and the receiver, which can be 'touched' or not by the message.

The issuer is essentially the one who wants to convey a message and therefore the taker of initiative. He is responsible for the communication strategy and the choice of channels. It is also the one who has the most to lose in the case of communication failure with the receiver. The target of a message is commonly referred to as the receiver. The message must be designed for its attention and the strategy must ensure that it is understood.

State of the art in tourism communication: "The rapid expansion of international tourism as we know it today, with widespread business and leisure travel driven by continued deflation of travel prices, increased transport speed and comfort, and aging of the population, is often related to the general globalization of our society. This fact leads us to more and more frequent cases of relations and interactions with civilizations of different cultures. Under these circumstances, intercultural communication becomes a strategic issue for multinational economic enterprises and major tourist destinations" [6].

In a context of highly diversified international markets, it must be recognized that some actors, such as Switzerland Tourism, are beginning to take these cultural elements into account, but only since recently.

As a matter of fact, if we compare for example the campaign "Cities 2011" [7] and the campaign "Grand Tour of Switzerland 2015" (ST, $2015 \mathrm{a}$ and b), we already see a great evolution. Indeed, the videos that can be found in the 2011 campaign to promote the "Swiss Cities" featured the same messages and codes on all markets [7]. Only the text and logo of Switzerland Tourism differed at the end of the video while the script, the actors, the traditional 'Paul and Sebi', etc... were the same for all markets.

To mark the evolution we can here clearly point out on the campaign of the Grand Tour of Switzerland in 2015 in China for example, a promotional video featuring a famous Chinese man experiencing activities that match their expectations better [8], such as simply drinking water at a public fountain.

Thus, in comparison, it can be noted that the video for the European markets has a totally different 'storyboard' with more representative and traditional actors [9]. However, these examples are still exceptional and the message communication strategy is too rarely adapted to the receiver (target audience). By this we mean of course the channels used, but also and especially the signals adopted. Although the texts are generally translated into different languages, the content of the message remains the same and does not take into account the various receptors cultural differences.

The complexity, and above all, the variety of the markets concerned and the means at the disposal of the tourist organizations can partly explain this state of affairs. According to data from the Swiss Federal Statistical Office 2014, the Chinese market continues to grow with nearly one million hotel overnights in 2013, making it the fifth largest foreign market after Germany, United Kingdom, USA and France.

However, some good practices have been observed in recent years, such as the initiative of Switzerland Tourism and Swiss Snowsports, which led to an effective intercultural communication with the arrival of Chinese ski instructors and bloggers at various Swiss ski resorts during the winter of 2013-2014.

During that winter season, it was no less than eight Chinese ski instructors who were invited to come and train in eight different swiss destinations (Davos, Engelberg, Grindelwald, Gstaad, St. Moritz, Verbier, Villars and Zermatt). They first attended the Swiss ski instructor training while occasionally accompanying Chinese tourists.

The role of these instructors was not limited to activities on the slopes, but also to link information to China. According to Simon Bosshart, director of the Asia-Pacific region for Switzerland Tourism, "the eight ski instructors proved to be excellent mediators to facilitate communication with Chinese hosts."

The impression left by the visited country on these instructors was so positive that they were delighted to continue to share their impressions of it in China. Among other things, they used the "Feichang Huaxue" application to share their impressions and advice with their compatriots on Switzerland as a winter holiday destination. This application has been downloaded 7000 times in China during the last four months of winter and remain completely unknown in Europe.

The impact of the media coverage of this initiative is also very pleasing with 48 articles spread over more than 100 pages and 45 minutes of video reportages that have been broadcast in the Chinese media. The pilot project was also closely monitored by the media in Germany, France, Austria, Norway, Sweden, Finland, the United States, India, Singapore, Hong Kong and New Zealand [3]. This shows how important the topic of multi-culturality is nowadays.

\section{Methodological findings (quantitative study)}

In order to try and verify our theory in the most representative way possible, our methodological choice tended towards a quantitative survey with the 'sphinx' software. We wanted to analyze the communications for two target countries (China and the Middle East) by identifying the type of themes chosen and what kind of "Swissness" we communicate to our interlocutors. The aim here is to identify the marketing impacts and the possible consequences in order to justify an improvement in our ways of communicating by considering cultural differences. The use of images seemed relevant to collect information by the insertion of visible and fixed objects. According to Moscarola, the wall of images makes an experiment possible by immersing the respondent in the interrogation of the survey: "Experience shows that these images facilitate the expression and enrichment of the multiple interpretations they may arouse".

Various image walls on subjects closely linked to the swiss economy were selected and classified according to their topic. Each respondent had to choose the image he preferred (best) and the one he liked the least for each wall. For each of these two categories (i.e. best and least), feelings were associated and it was asked to define the feeling closest to what the image made the respondent feel for each of the chosen photographs. In addition, when choosing 'best' or 'least', the respondent also had to define which content of the photograph prompted his choice by clicking on the referred area.

With this strategic vision, the Geneva School of Art and Design has 
been able to consolidate its preliminary research on "Swissness" and to offer a considerable number of images on the main economic themes of our country, defined by the same institution in advance.

In addition to studying the relationship of potential clients to the images, our methodology also allowed us to analyze the emotions aroused by the different images. The assessment is based on personal values and it is that which we have used to define well-being or unhappiness, and thus has helped us to determine the qualitative content of an emotional experience and its intensity. For our survey, it is an intuitive appraisal of the aspects perceived here and now, in situation. The information will allow us to draw conclusions about what is undesirable or favorable for the respondent. We are therefore inspired by emotional theorists who confirm that we cannot dissociate the motivational, affective and emotional components in the study of adaptive processes. According to Frijda, emotions are motivational states underlying certain modes of interaction with the environment.

There were, however, limitations to this study. In fact, thirty-four observations had selected two images of what they found to be best and two images of what they found to like least on some image walls which shows that part of the panel did not understand the question or were mistaken in manipulation.

The total sample of respondents consists of 280 fully completed questionnaires. Of these, 87 come from Switzerland, 78 from China, 64 from the European Union and 51 from other regions of the world. Given the lack of cultural ties, the disparate answers could not be used for this research.

Main findings: The first observation that has been made is that the degree and the importance of the bias in the differences of vision depend strongly on the themes and is neither linear nor strongly linked to one culture more than another. In other words, we have been able to observe a certain standardization of representations, proportionally counteracted by linearity ruptures displaying totally different representations on the same theme, depending on the origin of the respondents. Among the most appreciated images, all themed walls together, the elements related to water, mountains and well-being are the most often cited. For European customers, however, family and the presence of people are at the top whereas for the Chinese it is rather the elements related to the terroir and culture. It should be noted, however, that only identifiable cultural elements, such as traditional dance, have been acclaimed. On the contrary, they showed a certain restraint in the face of unknown elements (i.e. Alphorns).

The part of this survey that gave rise to the biggest differences concerns emotions related to images. Among the positive emotions, the word "happiness" is first among Chinese nationals (34.4\%). For the Swiss, it is the word "surprise" with $39.3 \%$, whereas for the Europeans it is the term "desire" which was acclaimed with $29.7 \%$. If we now consider the negative emotions, or related to the images mentioned as the less liked of the test, the word "fear" stands out for $41.4 \%$ of the Swiss. The Chinese, on the other hand, felt much more "sad" (32.6\%) at the sight of certain images whereas for the Europeans felt "anger" which predominated with $33.1 \%$ of the respondents. From a cultural point of view, it is very interesting to note that there is very little feeling of "anger" among Chinese respondents.

These first findings, mainly those related to feelings, already show a certain statistical difference between participants' perceptions depending on their origin. There is undoubtedly already a clear lesson to be learned here.
Among the various themes proposed, there was of course the gastronomy. In view of the Swiss traditions and habits, the "cheese" element appeared on several walls of the survey and in various forms. It is not surprising that this element is strongly rejected by the Chinese each time, whereas it is highly praised by the Swiss and Europeans. This ingredient raises feelings of "fear" and "disgust" among the citizens of China, while it is the "desire" for the Swiss and a sense of "happiness" among Europeans.

As far as the landscapes are concerned, none of the three provenances liked virgin landscapes with sober colors and without human presence, be it a mountain restaurant or an agricultural plain in winter. For a landscape to be enjoyable, it appears that soft and shimmering colors (white, green) and a presence of human activity are more appreciated than the mountain (gray) or the winter lower valley (brown).

The traditional Swiss chalet could not, of course, go unnoticed in this study. The associated images were particularly pleasing to our Chinese contacts who have felt "happiness" in front of these representations, whereas for Europeans it is rather "wonder". The Swiss were slightly less sensitive to this argument.

Culture has of course also been treated from various angles. For the Chinese, it was the images related to dance and traditional costumes that attracted their favors. An image with traditional dancers even provoked a sense of "happiness" for $89 \%$ of them. The Swiss and the Europeans were much more sensitive to the elements of traditional music, especially to the alphorn, which was not at all put forward by the Chinese.

\section{Organizational innovation}

There is no single definition of organizational innovation. In his thesis, Dubouloz [10] defines it as a non-technological process innovation that includes new practices, tools, processes, techniques and organizational structures for the company adopting them to improve the efficiency and effectiveness of internal organizational processes. The lack of academic interest in this form of "non-technological" innovation is paradoxical if we refer to the Community Innovation Surveys' results. Indeed, the Oslo Manual defines it as the adoption of new organizational methods in company practices, both in the workplace and in external relations [11]. This is why we are interested in the sources of creativity in the innovation process that we consider as original forms of knowledge and experience rather than the emergence of ideas.

State of the art: Setting up an organizational innovation requires thinking of the organization as an "improbable" experimental space combining two distinct, opposing but evolving operations: learning and unlearning. The literature distinguishes two approaches.

The first one is behavioral and is characterized by a modification of the actors' behavior according to sequences stimulus - responses adapted. The contributions of Scharmer [12] and Sarasvathy [13] show that this type of learning is dependent on the past and is based on "routines".

The second stream is cognitive; here the representations determine the actions of the actors. It is therefore the treatment of information which guides the actions of the people according to their knowledge and their mental representations. This option validates non-routine situations, experiences in which actors must "reformulate" reality, or challenge the values that are the foundation of actions. This position 
seems to be the most relevant to us in the face of the changing economic context in the touristic field as we see it today.

From then on, it seemed appropriate to integrate the concept of "cognitive capitalization" into our organizational model. This implies an ability to develop learning permanently, both individually and collectively. This participatory approach is therefore of real interest from the governance point of view. We have shown that the interest in the development of an innovative design is obvious and requires a collective dimension of the project. However, we are doubtful about the actual capacity to hybridize today's resources among various partners. This raises the question of the formal framework of our organizational model, the explanation of the stages and the mode of decisive collaboration for the innovation process success.

Indeed, when a company innovates, the main source of uncertainty lies outside the organization, whereas, on the other hand, it is a process whose management will depend on the internal representations of the leaders of the company. Two clash management models: a traditional "linear" model and a "vortex" model. The latter is more appropriate for experimenting, dealing with actors and increasing the ownership of the project by a large number of actors [14].

Durand notes that contemporary and western organizations struggle to manage the complexity of the issues they face. Leur modèle d'action est souvent basé sur une logique de gestion qui se concrétise par l'omniprésence du contrôle. To remedy this, the author proposes to transform organizations to promote "the emergence of collective intelligence". This requires the development of specific skills such as managing uncertainty and exploring the unknown. From a managerial point of view, this is a questioning of the modes of governance focused on the control procedures in order to try to exercise a "collaborative leadership" and find a collective way appropriated to the current challenges. This is what Scharmer [12] calls "co-creation," a thought that belongs to a group, a community emerging from personal and collective experience. We will develop this perspective of organizational transformation by focusing on Sarasvathy's [15] research on "achievement" demonstrating how entrepreneurialism is unpredictable and that the goals emerge with the deployment of the project.
The innovation process: In a highly competitive environment, there is usually a strategic tension between the "operation" of existing activities and the "exploration" of new areas of activity [16]. The aim is to strike a balance between preserving the best skills of the company and its ability to change in order to cope with rapid changes in the environment [17].

This approach has been confirmed by Sarasvathy's [15] theory of realization, which defines entrepreneurship as "non-predictable" and "emerging" objectives as the project progresses: Effect is a model of non-predictive decision making. The theory of performing offers a relevant transformation model in an innovation process that focuses on analyzing the resources available in relation to the opportunities available to the organization rather than to a previously defined target. This vision, described below, starts from the "inside" and only works through interaction with other stakeholders: You begin with the world as is, merely the small part of it that is accessible to you in particular, and perform a series of effectual transformations on it that ends be creating imagined, unimagined and even unimaginable new worlds. In effectual logic, it is understood that ends exist in hierarchies and that ends and means are dialogically intertwined (Figure 1) [13].

The realization approach integrates uncertainty as a variable in the development process of innovative projects. Nevertheless, causation and enforcement do not conflict, as soon as the right target has been identified, we must be able to resort to "causal" processes, such as marketing.

Immersion in the management of "complexity" becomes a sine qua non condition. Within the framework of our protocol, we have found that it can also be the source of "reactive tensions" between the partners when it comes to developing "creative tensions" in the sense of Senge [18]. This property is essential in the management of our model. It takes into account the dialogical relationship between order and disorder because an innovative organization is a place where organized phenomena can arise from disorder.

Resistance to change: Theory defines the process of innovation as an accumulation and destruction of knowledge, the renunciation of certain practices of the past, and the elimination of certain options for

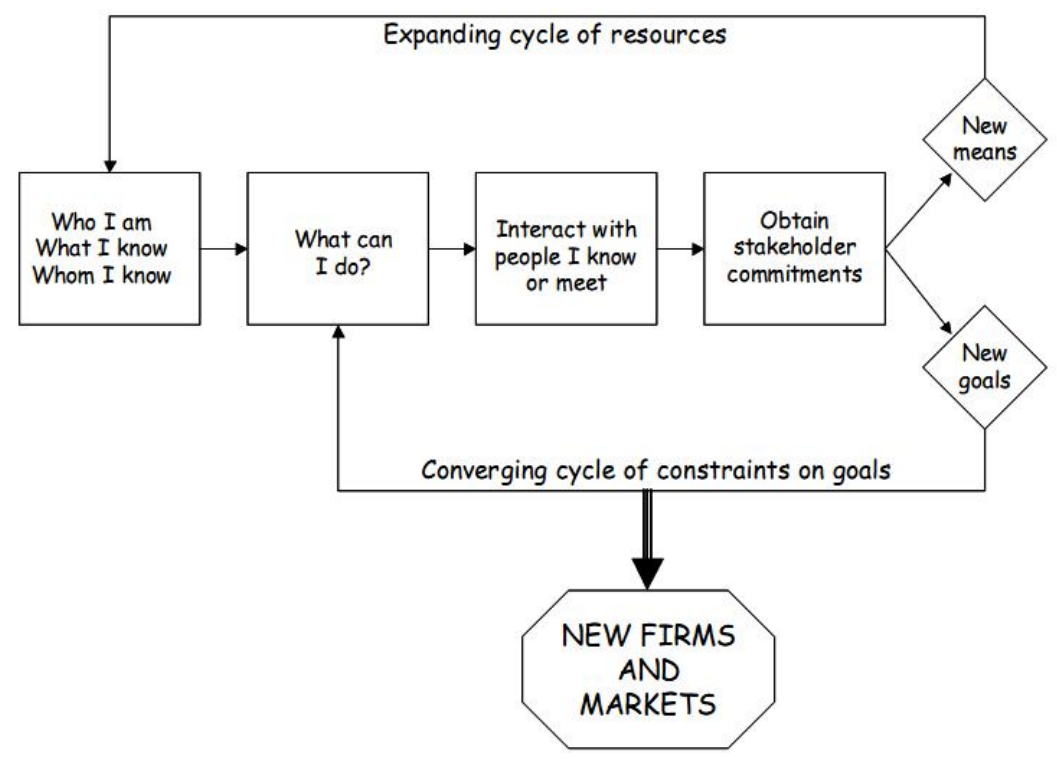

Figure 1: New firms and markets. 
the future. This process generates "resistance to change", a process that is seen as a force opposed to the reorganization of behavior and the acquisition of new skills.

Our assumption is that a type of organization can favor a new, more effective communication paradigm by significantly reducing the resistances to change present in Swiss tourist organizations. Our experience has shown that despite the praise of leadership, talent management and "agile" methods, the resistance to change within the leaders of tourism companies remains high even as they look for alternatives to the dominant models!

It should be noted that the barriers created by managers and employees in the face of the change engendered by organizational innovation are "internal" and that they would be the most difficult to thwart. The results of research carried out by Dubouloz [10] are also promising: contrairement aux conclusions de Tourigny et selon lesquelles les rigidités organisationnelles [résistance au changement] sont des barrières infranchissables, nos résultats montrent que les entreprises qui ont réussi à pérenniser l'usage de l'innovation organisationnelle, sont parvenues à les minimiser (voire même à transcender le processus d'IO) à l'aide de pratiques de management (participation des salariés à l'élaboration des plans de mise en œuvre, démonstration par la formation, démonstration par les résultats sur le terrain).

It is interesting to note that, today, literature agrees that organizations have faced major changes over the last decade. These are called "reorganization", "restructuring" or even "revitalization". This organizational dynamic is the repercussion of other changes such as markets globalization, economy globalization or international competitiveness. These organizational changes mean significant changes in the company to remain competitive while adapting to specific industry and/or service environment changes. The analysis of compiled statistics on the success rates of organizational changes shows that half of the transformations (strategic change) do not reach the expected objectives [4]: Parmi les causes connues, on trouve une faible capacité organisationnelle à soutenir les changements, un leadership ambivalent ou évanescent, un manque de légitimité et d'ambition envers les changements des réseaux de communication insuffisants, une inertie organisationnelle forte causée par la culture et la structure en place et, bien sûr, la résistance au changement des acteurs concernés.

The classic approach to organizational change relies almost entirely on the notion of resistance to change. Bareil [4] shows that there is a variety of behavioral responses to organizational change and that they may change over time. The "phase of concerns" model defines a probable sequence of legitimate concerns, considering that each actor will experience normal concerns generated by a tension between the need for security and the desire for change: Le concept de préoccupation (ou d'inquiétude) réfère à un construit cognitivo-affectif qui exprime une réalité émotionnelle vécue et un état inassouvi de l'esprit qui est orienté vers un objet. (...) Il faut se rappeler que ce n'est qu'une fois rendu à la phase 5 (préoccupations centrées sur l'expérimentation), que le destinataire est ouvert à l'apprentissage et à la formation, c'està-dire qu'il est disponible et disposé à faire des efforts pour changer ses habitudes [4].

If individuals learn from their experience, this does not mean that the organization learns. Process is neither sequential nor hierarchical, but organizational learning has its roots in that of the actors of the organization. It is therefore our own mental schemas that prevent individuals and organizations from expressing new modalities of understanding. Trapped in their cognitive net, the organization and its actors are limited to performing "simple loop" learning, which modifies the strategies that underlie it without undermining the fundamentals of these theories of action [19]. These cognitive impediments can be removed from the moment when we introduce a reflection and deeper change actions in terms of the underlying values of the organization: double-loop learning.

In summary, to develop a willingness to innovate, leaders must create communities that share a motivation, values and rules of engagement. In terms of innovation, classical process-oriented procedures are detrimental to exploration innovation: tourism is experiencing this tension very strongly. We must therefore be aware that innovation implies change and that, by definition, the change that emerges is not a priori known in advance. By performing this step collectively, we assume that this will facilitate the creation of a community feeling, which is the key that innovation needs. It is only when leaving the security zone that a source of creativity can be revealed.

The co-creation process: This process is not just a creative realization between a few people. For Scharmer [12], "co-creating" requires the continuous integration of feedback from key partners to "dialogue", mainly with clients. It is a matter of exploring, as Scharmer says "the future through action", which calls for a qualitative change in thought. Scharmer relies on the Baetson theses of the Palo Alto School and Peter Senge, which demonstrate that a change of "type 2" necessarily implies a learning process that affects and modifies the system itself.

In this sense, the process of co-creation implies a managerial change. Because it summons not only all parts of a system to effect a dynamic of change, which is already a structural break, but above all it fosters a dynamic where unlearning precedes a phase of new learning. This is what Scharmer calls "letting go" and "letting come": l'émergence de nouvelles images de nouvelles expressions; surprendre est toujours une bonne façon de faire, suspendre le jugement. La panoplie est sans fin, des arts classiques aux nouvelles technologies (The emergence of new images of new expressions; Surprise is always a good way to do, suspend the judgment. The range is endless, from classical to new technologies). The generation of atypical situations or environments facilitates this process of unlearning because participants must adopt a new role, involving new forms of organization (Figure 2).

Although the literature seems unanimous on the commitment of all stakeholders, the transposition of this concept in the management of an organization tended to innovation requires the use of several dimensions: collective, exploration and sociocognitive conflict2. The role of the leaders of innovative organizations is not only to define and then control the direction to be followed but to create and nurture an ecosystem favorable for the emergence of creative interactions. This is a crucial evolution of the perception of managerial responsibility in the service of a creative community.

In summary, the cognitivist approach we have chosen makes these non-routine actions possible. The development of an atypical organization becomes, in itself, a context of learning from breaks that the participants will experience during the co-creation process. The management and the management system are then fundamental to secure the actors. They become aware that they are not doing what they usually do and that "something is happening". It is the transition from a model of causal decision to an effective logic (Sarasvathy, 2001).

Process: Relation with LGM/ST/CMT $>>$ change of strategy. In the more specific area of tourism that faces economic, social and environmental challenges, we believe that the innovation process 


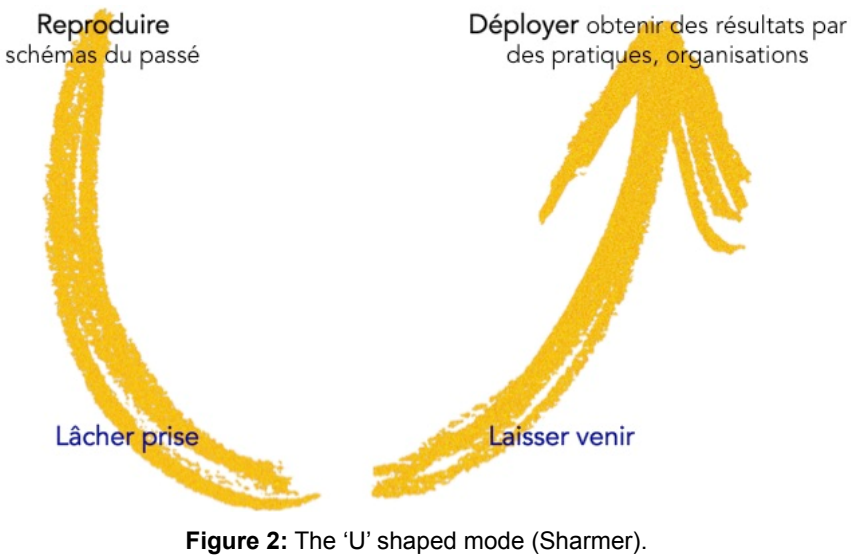

emanates more from one form of organization than from the development of new communication technologies. The literature often refers to the concept of "cluster", which is defined as a grouping of firms in the same networking sector to transform economic challenges into opportunities rather than threats. This is a systemic response to the challenges that this industry faces with all the players of a territory.

However, this does not create a paradigm shift in the way we imagine new commercial communication strategies. Clergeau and Violier [20] show that the transfer of such a scientific tool developed in the industrial field cannot be transposed as such in the field of tourism: the production of a tourist experience is done by the tourist who mobilizes resources and services to live its experience on the territory where they are co-invented and co-produced. To take into account the specificity of tourism activity, the research must integrate the cocreative and co-productive dimension of tourism, and in fact enrich the concept of "cluster". The latter must therefore be revisited today in the sense of trying to understand "territorial organization" as a coproduction of experience, the client becoming a "service co-producer".

The question of the role, and therefore of the relational modes between the actors, is preponderant. We were able to verify with organizations like Lake Geneva Matterhorn Region (LGMR), Suisse Tourisme or Crans-Montana Congrès that these were either organizations in clusters or networked arrangements, as Ménard [21] clarifies a partial transfer of the power to allocate resources without simultaneous transfer of property rights. The consequence was straightforward: as soon as it was a matter of modifying their organization and investing resources in a logic of the effective type, we were faced with a refusal, despite the obvious interest of the various leaders.

2 Within the framework of collective intelligence in interactions, the sociocognitive conflict triggers imbalances in thought, thus making the process of elaboration necessary. It is the source of both social and cognitive imbalance. It is then said that the sociocognitive conflict is reabsorbed by the transition to a more complex cognitive model of the situation.

From the perspective of our research, we were interested in a "hybrid" form of structures. This mode of organization generates a form of governance in which dependence demands a continuity of relations and requires mechanisms of coordination and a more powerful control than those of the market, without, however, establishing an economically and legally independent entity. The problem then arises of knowing what are the exact properties of such structures [21]. This is exactly the tipping point that we have not been able to overcome during our consultations.

Steven's [22] research on renewal of value chain and innovation models shows that modes of association and governance are the key success factors for innovative firms making this interesting observation: co-creation establishes a mutual dependence between actors of innovation and the innovative firm. On the one hand, organizations are not in a position to fully control the activity of developers who work outside of any relationship of hardship. On the other hand, developers and users have the power to influence the choices and options taken throughout development. There is thus a relationship of mutual dependence between organizations and cocreators [22]. Thus, the development of co-creation practices generates a "functional rupture" in the sense that the actors contribute as much to its development as to capture a part of its profit. The position in the creative process, the substitutable nature of the competencies provided, the role in governance and the animation of the network will determine the capacity of the actors to capture part of the value produced or to use all or part of it in its own process [22].

Co-creation workshop: The realization of a co-creation workshop is aimed at several objectives: bringing together actors from different cultures who participated in the analysis of the wall of images, creating a panel of functions (management, marketing manager, site manager) and of various universes (Chinese culture, gender and age), gathering different forms of organizations and diverse industries (Anniviers Tourisme, Montreux Tourisme, Nestlé, Suisse Tourisme, Sunrise, Yverdon Tourisme), in order to experiment the process of emergence at the service of innovation and the change of an intercultural communication model.

We used the Goffin and Mitchell model to locate potential sources of uncertainty in the implementation of an innovative organization generating a co-creation process (Figure 3 ).

The first observation is that companies develop an approach of "exploitation" rather than "exploration", like a strategy based on acquired skills and cost containment rather than innovation.

Secondly, organizational culture differences are more pronounced in tourism, which uses few creative techniques, while other industries rely on $\mathrm{R} \& \mathrm{D}$ services.

It is interesting to make the link with research on the impact of creative techniques, which, although have not shown that they increase the emergence of entrepreneurship, allow reflexivity. This metadiscours 

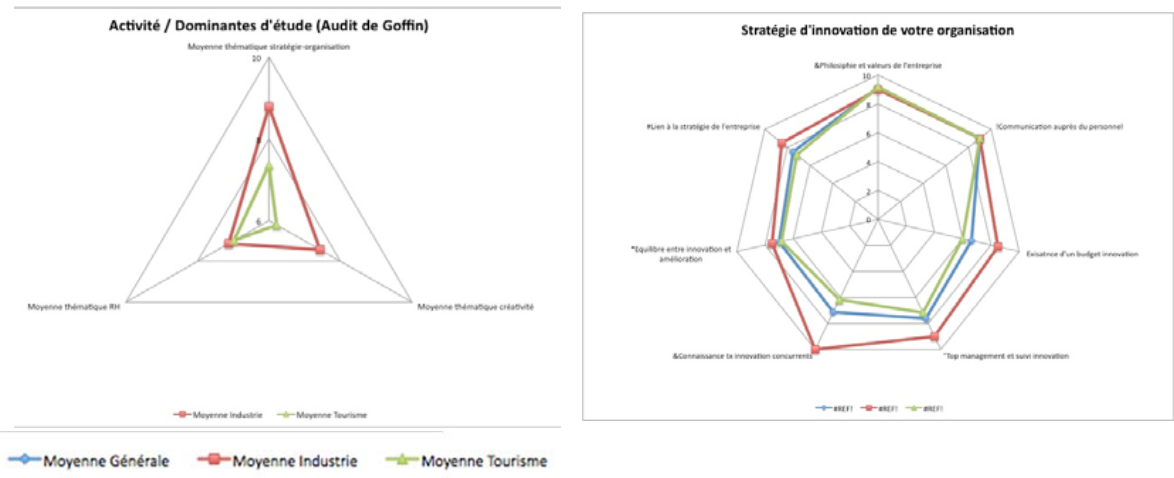

Figure 3: Comparison of audit dominance between tourism and other industries.

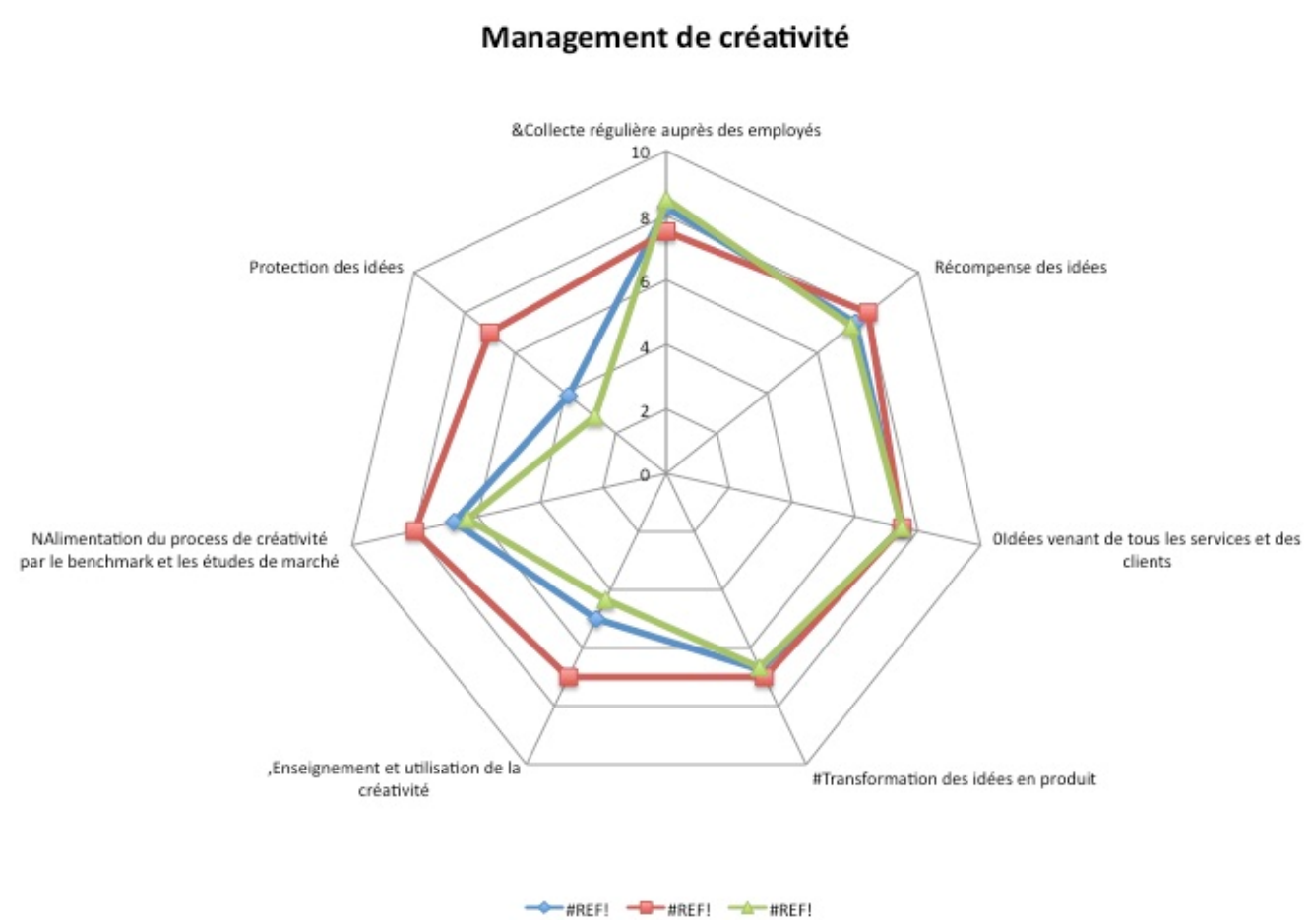

Figure 4: Management of creativity.

allows one to go further in the linking of the desirable and the feasible: it reveals tensions and compromises to be found between these two beliefs [23]. This analysis suggests that tourism companies would benefit from their intentions, which would allow them to develop an effective approach, thus making the transition to a culture of innovation (Figure 4).

Here again, the results suggest that tourism does not formally resort to creative techniques - or knowledge. Two elements seem critical: the lack of prioritization and the choice of a governance model.

\section{The evaluation of innovative projects}

The results are paradoxical. On the one hand, the notion of innovation projects is connoted as "strategically important", in terms of developing new markets, better competitive positioning and hence expectation of profit. On the other hand, they relate only to indicators of profitability; so a causal logic of the process at the expense of an effective logic.
The relevant mode of governance for the development of innovative projects

Our survey shows that there are few skills identified by professionals to support innovation projects. This situation raises the question of the implementation of an additional organization within - or in parallel with - existing and traditional organizations. Not being able to identify other visions could be the signal that companies want to innovate, but without global change.

This point will be an important element for the presentation of our organizational model, in particular in terms of risk reduction and maximization of the co-creation process.

\section{Result}

In the context of our research, we formulated the following hypothesis: 


\section{The natural resistance to change of organizations in place has significant inertia}

The technology adoption lifecycle passes through identified phases leading to a "peak of waiting" followed by a "period of disappointment" and finally the "recognition" through a recurring "set of productivity". This adopted cycle can be extended to any innovative project (Figure 5).

\section{Participatory infatuation does not occur naturally}

The innovation process depends on cognitive aspects and social interactions. Engaging a change in relation to past automations closes any possibility of "learning from the future". However, innovation is characterized by uncertainty and therefore by the ability to reformulate our mental patterns. The descent of the U-shaped process may correspond to a feeling of "regression" or "resistance" in the actors; while in our model it is an opportunity to open up new ways of thinking, to communicate, to collaborate and ultimately to create concrete applications responding to strategic innovation issues (Figure 6).

The language of participatory narrative is still in its early stages

In this sense, our organizational model aims to reduce the risks of resistance to change by identifying the concerns of all actors at three key moments in the organizational innovation process. Our model:

- Favors a collective approach upstream by defining a common intention and management of the explicit commitment of the stakeholders;

- Is oriented towards a cognitive dynamic, namely the accompaniment of emerging knowledge (process of individual and collective learning);

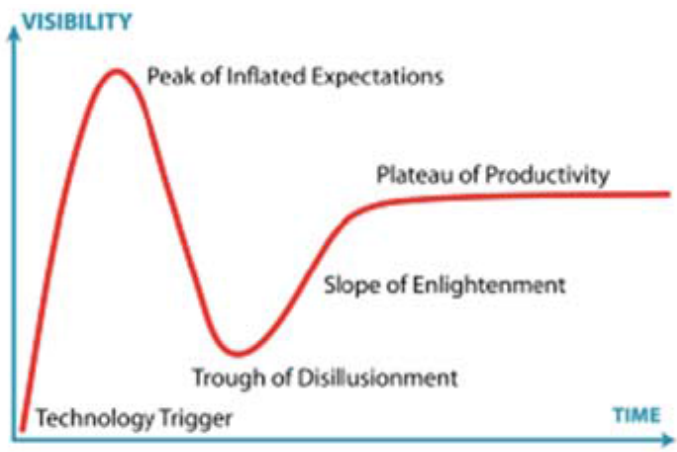

Figure 5: Gartner Hype Cycle.

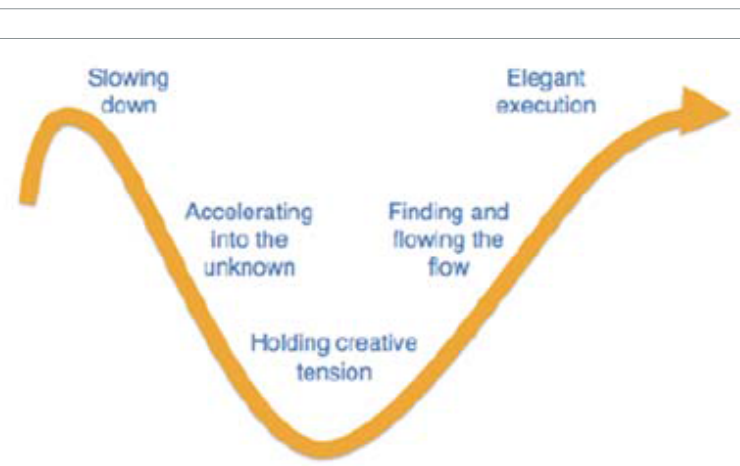

Figure 6: U-shaped process.
- Renews collective learning with ease and efficiency.

The co-creation process corresponds to a learning flow within the framework of "meta-organizations", which are experiencing new forms of coordination of activities: a scientific pole that develops and codifies knowledge (cognitive capitalization), a technical pole that provides products or services (intercultural communication, marketing) and a market pole comprising users who express an expectation (agile approach).

\section{Innovative organization model of a company's dynamic innovation capacity}

Since the main barriers to innovation are mainly built on the basis of human biases that hamper exploration and learning, we pay particular attention to explaining the different stages in order to reassure the actors during the process of innovation. This approach has several advantages. First, it is compatible with agility, understood as iterative project management, focusing on the roles of people and the interactions at the level of processes and tools. Then, it tests its effectiveness and its effects on productivity and well-being. Finally, as a "black hole", it has the effect of attracting to it successive parts of the company in a viral way. In conclusion, it reduces the risk of nonlearning, acts and encourages life-size experimentation. Here, the back and forth between knowledge and organization is localized and allows the adaptation to the particular conditions of each company (Figure 7).

\section{Results on intercultural communication}

On the basis of the results of our intercultural survey, we found that the image we show of Switzerland is not necessarily meaningful to visitors from other cultures. We project a stereotypical image of Switzerland. We have demonstrated that the success of intercultural communication implies that the creation of a message relies on an interaction between transmitter and receiver.

\section{Degree of innovation in relation to the state of art}

This project is the first one to focus on the simultaneous use of three diagnostic approaches: Pentathlon audit, process of implementation and co-creation process in the field of organizational innovation. It is difficult for companies with operating experience of innovation, organized around procedures acquired in project management, to switch to an exploration logic and develop this "strategic flexibility" in order to create a hybrid structure. Hence, this project is innovative because it proposes a new logic of prototyping to companies willing to innovate (product, service, business model, communication, organization).

The added value of this approach consists of accountability and reducing risks. This mitigation takes place at three levels: at the level of the market, at the level of costs and at the organizational level. Indeed, here the notion of rupture is replaced by that of creative evolution because even if the result can lead to a redistribution of the commercial priorities of the company, it will only be the expression of its social and cognitive development. Thus what appeared to be a danger, namely a radical modification of the whole organizational structure, disappears in favor of an evolution of knowledge relations and working methods not only at smaller scales but above all diffused on longer periods corresponding to those of apprenticeships. Innovation is therefore no longer an "innovate or die" type of injunction, but an internal device for exploring company specific possibilities. The speed of exploration and its intensity will no longer be evaluated in terms of the speed of 


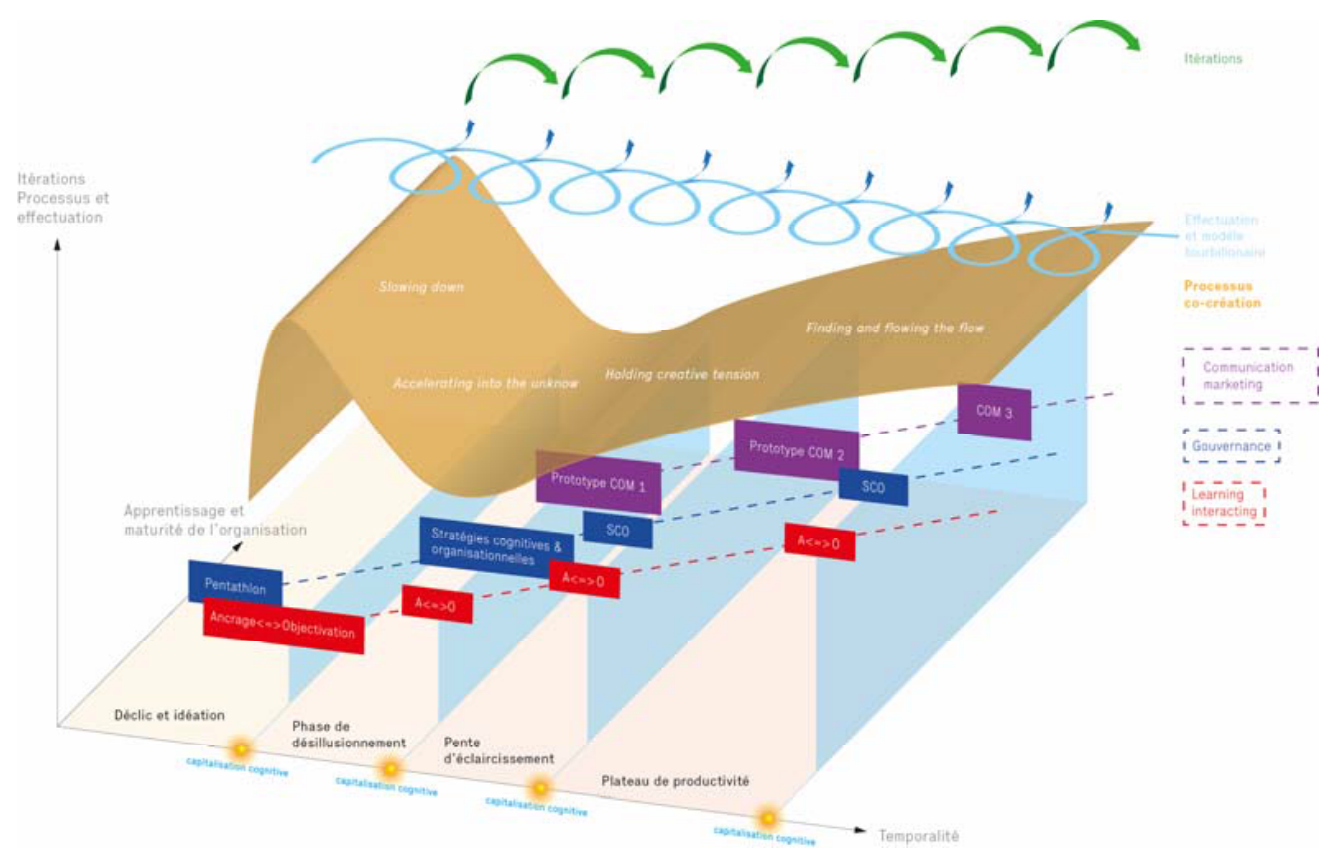

Figure 7: Company’s dynamic innovation capacity.

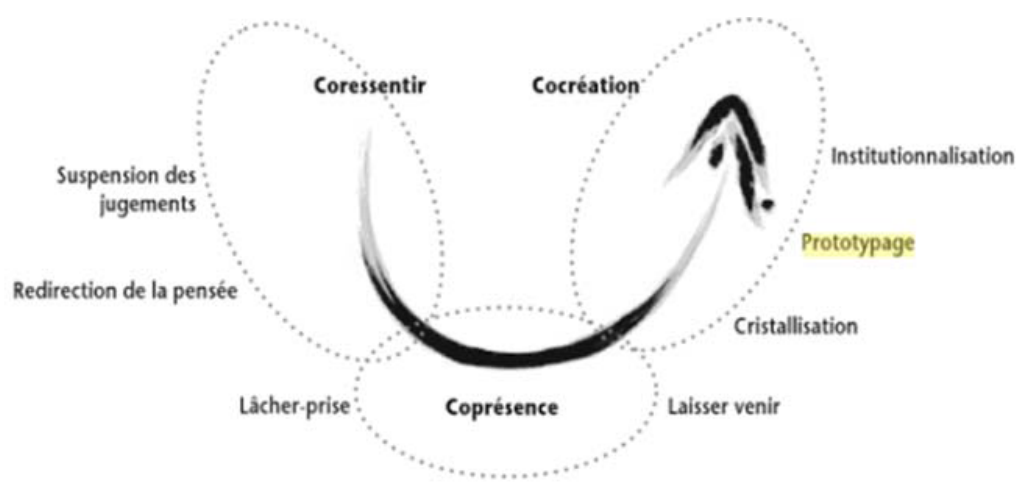

Figure 8: Scharmer's U-shaped curve (Scharmer [12]).

integration of exogenous models, but in terms of connectivity and savoir-faire. The advantages for companies are considerable: firstly, a reduction in anxiety and therefore resistance to innovation, then a much better development strategy, and finally a strengthening of the competitive advantages specific to each company.

\section{Theoretical contribution}

Our concept is based on the possibility of designing new models of strategic flexibility in order to improve the co-construction and creation systems. It is a question of responding to each request in a targeted way in relation to each issue. This study confirms the organizational learning studies developed by March [16] showing that the survival and prosperity of an organization leans on a clever balance between the exploitation of controlled activities and the exploration of new paths. Our results will allow us to develop what Chanal and Mothe [17] define as a dynamic capacity of innovation, namely the ability to combine operating and exploration innovations (Figure 8) [24-27].

\section{References}

1. Mkono M (2010) The Future of Tourism in Zimbabwe: Towards Sustainability? Tourism Analysis 15: 387-391.

2. Jaakola E, Alexander M (2014) Customer Engagement: Contemporary Issues and Challenges.

3. Suisse Tourisme (2014) Ideale Botschafter des Schweizer Winters: Chinesische Skilehrer reisen zurück. Récupéré sur.

4. Bareil C (2008) Demystifying resistance to change: question, findings and implications for the experience of change. Telescope 14: 89-105.

5. Perret V (1996) Organizational change management: Articulation of ambivalent representations. Article (successful research) presented at the 5th International Strategic Management Conference. Lille: May 1996.

6. Tsiotsou R, Ratten V (2010) Future research directions in tourism marketing Marketing Intelligence \& Planning 28: 533s544.

7. China ST, Beijing (2011) City. Récupéré sur

8. Suisse Tourisme (2015b) Grand Tour of Switzerland . Récupéré sur.

9. Suisse Tourisme. (2015a, 15 avril). The Brand New Grand Tour of Switzerland [Video]. Récupéré sur. 
Citation: Broccard M, Pillet A, Baratelli J (2017) Innovation in the Concepts of Intercultural Communication and Resistance to Changes in Responsible Organisations. J Tourism Hospit 6: 314. doi: 10.4172/2167-0269.1000314

Page 10 of 10

10. Dubouloz S (2013) Organizational change management: Articulation of ambivalent representations. Article (successful research) presented at the 5th International Strategic Management Conference. Lille: May.

11. Organisation for economic co-operation and development statistical office of the european communities (OECD) (2005) Oslo Manual. Guidelines for collecting and interpreting innovation data (3rdedn).

12. Scharmer O (2012) Theory U: Leading from the Emerging Future. Orleans: Pearson Education.

13. Sarasvathy S, Germain O (2011) Execution, a pragmatic and pragmatic approach to entrepreneurship. Review of Entrepreneurship 3: 67-72

14. Alter N (1996) Sociology of business and innovation. Paris: PUF.

15. Saravathy SD (2001) Causation and effectuation: toward a theoretical shift from economic inevitability to entrepreneurial contingency. Academy of management Review 26: 243-263.

16. March J (1991) Exploration and Exploitation in Organizational Learning. Organization Science 2: 71-87.

17. Chanal V, Mothe C (2005) Reconcile exploitation and exploration innovations. The case of the automobile sector. French Management Review 1: 173-191.

18. Senge $P$ (2006) The fifth discipline. Leverage learning organizations. Paris: Eyrolles.

19. Gravel N (2010) For a sustainable development of knowledge: the collaborative approach of a community of practice in the service of organizational learning Telescope 16: 168-192.

20. Clergeau C, Violier $P$ (2012) Is the cluster concept soluble in tourism? TEOROS 31: $60-71$.

21. Ménard C (1994) Rational Behavior and Cooperation: The Organizationa Dilemma. In: Frydman R (ed.) What hypotheses of rationality for economic theory? Cahiers of Political Economy, 24-25.

22. Stevens E (2009) Value Co-creation and User Communities: Towards a Renewal of Value Chain and Innovation Models. Management \& Future 8: 230244.

23. Hernandez EM, Redien-Collot R (2013) Efficiency and entrepreneuria disclosure: the role of creativity techniques. Review of Entrepreneurship 4: 11-34.

24. Durand C (2012) The art of making collective intelligence emerge as a process of change emerges. In: Mahy I, Carle P (eds.) Theory U. Emerging Change and Innovation. Models, Applications and Criticism, Quebec: University of Quebec Press.

25. Goffin K, Mitchell R(2005) Innovation management. Strategy and implementation using the pentathlon framework. New York: Palgrave macmillan.

26. Sarasvathy SD (2008) Effectuation of Entrepreneurial Expertise. Edward Elgar.

27. Emarketing.fr. (2015) Définition: Consommacteur (ou Consom'acteur). Récupéré sur. 